See discussions, stats, and author profiles for this publication at: https://www.researchgate.net/publication/263351245

\title{
Design Science Approach to Measure Productivity in Agile Software Development
}

Conference Paper in Communications in Computer and Information Science · November 2012

DOI: $10.1007 / 978-3-642-33681-2 \_15$

CITATIONS

2

4 authors:

Richard Vidgen

UNSW Sydney

187 PUBLICATIONS 5,846 CITATIONS

SEE PROFILE

(38) Sabine Matook

( The University of Queensland

51 PUBLICATIONS 685 CITATIONS

SEE PROFILE
READS

600

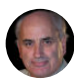

Brian Donnellan

National University of Ireland, Maynooth

144 PUBLICATIONS 1,064 CITATIONS

SEE PROFILE

Kieran Conboy

National University of Ireland, Galway

189 PUBLICATIONS 3,957 CITATIONS

SEE PROFILE

Some of the authors of this publication are also working on these related projects:

Project $\quad$ Agile and Lean Project Management View project

CROWDSOURCING PRACTICES FOR PUBLIC SCIENTIFIC RESEARCH FUNDING AGENCIES View project 


\title{
Design Science Approach to Measure Productivity in Agile Software Development
}

\author{
Richard Vidgen ${ }^{1}$, Brian Donnellan ${ }^{2}$, Sabine Matook ${ }^{3}$, and Kieran Conboy ${ }^{1}$ \\ ${ }^{1}$ Univeristy of New South Wales, Australian School of Business, \\ Sydney NSW 2052, Australia \\ r.vidgen, k. conboy@unsw. edu . au \\ ${ }^{2}$ Innovation Value Institute, National University of Ireland, Maynooth, Ireland \\ brian.donnellan@nuim. ie \\ ${ }^{3}$ The University of Queensland, UQ Business School, 4072 Brisbane, QLD, Australia \\ s.matook@business.uq.edu.au
}

\begin{abstract}
While adoption of agile software methods is high, little hard, rigorous evidence exists as to the success of these approaches. This paper describes the design science process that will be used to create a measure for productivity in agile development environments. We consider design science to be suitable because measuring performance in software development is laden with issues around measurability, ambiguity and imperfection. As a result, we need the rigor that design science brings while still maintaining relevance.
\end{abstract}

Keywords: design science, agile development, productivity.

\section{Introduction}

Agile software development approaches have been widely regarded as being highly effective. Many case studies report success stories from agile development projects, citing faster delivery, more satisfied and happier customers, and less bugs [e.g., 1].

Despite the substantial amount of books, journal papers, and industry reports reporting the effectiveness of agile methods, there is a lack of hard evidence to support this view [2]. The absence of measures in agile may be attributed to the people focus of the approach: agile software development assumes a collaborative and interactive environment in which developers and customers are highly motivated to work together to co-create valuable, working software [3].

To address this lack of rigor, the authors plan to identify and evaluate a set of measures for agile development. Given the focus on rigor, the development of a core set of artifacts - and the need for comprehensive evaluation and communication - the authors decided to adopt a design science (DS) approach to the research.

We begin by discussing the relevant literature on DS in Section 2, concluding with a description of the DS research (DSR) process that will be used as the basis for this study. Section 3 then describes the structure of the research for this study, based on the process model in Section 2. In section 4 we draw on the application of DS in this paper to reflect more broadly on the DS process.

M. Helfert and B. Donnellan (Eds.): EDSS 2011, CCIS 286, pp. 171-177, 2012.

๑) Springer-Verlag Berlin Heidelberg 2012 


\section{Design Science}

Design activities are central to most applied disciplines, and DSR has a long history in many fields including architecture, engineering, education, psychology and the fine arts [4]. While there is no widely accepted definition of DSR, when distinguishing between DSR and Action Research, Ilvari and Venable [5] defined DSR as a research activity that invents or builds new, innovative artifacts for solving problems or achieving improvements. Such new and innovative artifacts create new reality, rather than explaining existing reality or helping to make sense of it [6].

The DSR paradigm is highly relevant to IS research because it directly addresses two of the key issues of the discipline: the central role of the IT artifact in IS research $([7,8])$ and the perceived lack of relevance of IS research to the business [8]. DS seeks to create innovations that define the ideas, practices, technical capabilities, and products through which the analysis, design, implementation, and use of IS can be effectively and efficiently accomplished.

The result of DSR in IS is, by definition, a purposeful artifact created to address an important organizational problem. An IT artifact represents "any designed solution that solves a problem in context." [9], p. 4-5. Artifacts can be innovations that provide a degree of novelty into an application context.

March and Smith [10] identify two design processes and four design artifacts produced by DSR in IS. The two processes are build and evaluate, and the four artifacts are constructs, models, methods, and instantiations. The role of artifacts is to address heretofore unsolved problems; the artifacts are evaluated with respect to the utility provided in solving those problems. The design of the artifact is a non-linear process in which uncertainty, uniqueness and conflict can emerge.

A central concern of DSR has been the development of a systematic and processoriented approach to design and the practical application of such approaches [36]. Pfeffers et al. [11] designed and demonstrated a process for carrying out design science (DS) research in information systems and demonstrated use of the process to conduct research in four case studies. The purpose was to develop a DSR process (DSRP) model that would meet three objectives: it would be consistent with prior literature; be a nominal process model for doing DS research, and provide a mental model for presenting and appreciating DS research in IS.

\section{Illustration: Productivity Measurement in Agile Software Development}

In this section, we use Pfeffer's et al. [11] DSR process to present the design of a measurement system for agile software development projects. Figure 1 summarizes the artifact creation. Our entry point in the creation process is at the objective phase and thus, specific for and focused on a tangible outcome. 


\subsection{Problem Identification and Motivation}

First, the problem is defined and motivated [11]. Our problem space is agile development where a measure gap impairs project success. We suggest to address the agile metrics gap by applying "lean thinking" [2]. This is a "management approach that emphasizes creating value for end customers and eliminating activities that are not value-adding (waste)" $[3,12]$. Lean thinking is rooted in the manufacturing industry and can be traced back to Toyota's 1950s Production System [13].

\subsection{Objectives of a Solution}

In the second stage, the objectives of the solution are specified [11]. In our case, the objective is the creation of a system for agile software development projects to measure the productivity of these projects. Hence, we aim to achieve the following three objectives with the novel artifact: (1) Measurement of agile productivity at any stage of the development process; (2) Identification of areas in the process that can be improved to achieve higher productivity; (3) Control and comparison of the agile development process across teams within a firm and across firms.

\subsection{Design and Development}

In this third stage, the artifact will be created [11]. First, we do a literaure review on lean management metrics. Second, we translate the measures to the agile software development context. This translation process needs to be sensitive to the similarities and differences between lean management and agile software development. For example, lean does not appreciate people centred practices and rather promotes automated work flow tools, progress measures and simulations [12].

\subsection{Demonstration}

In this stage, the problem solving capability of the artifact is demonstrated [11]. To demonstrate the use of the measurement system to solve the existing gap in productivity, we plan to conduct field interventions in firms.

\subsection{Evaluation}

The evaluation focuses on empirical evidence for the effectiveness of the artifact but also on the degree of goal/objective achievement [11]. During the field interventions, participatory observations and interviews will be conducted with development teams and also particular individuals (e.g., managers, developers).

\subsection{Communication}

Communiction of the novel artifact but also of the entire design process will be undertaken [11]. For our research, we target scholary and practitioner outlets. 


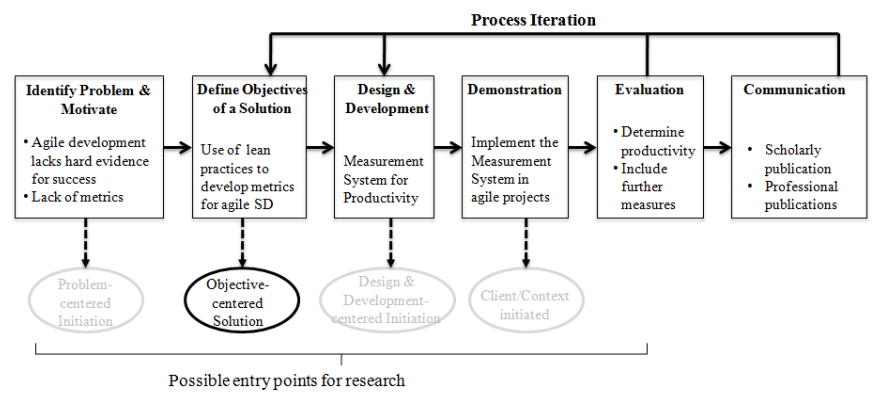

Fig. 1. The design science process applied in this study

\section{Reflections on the Design Science Process}

In applying the Peffers et al. [11] DSRM we encounter a number of issues - both practical and theoretical. A burning question for the design scientist is what constitutes an 'artifact'. Hevner et al. [6] posit how we might design artifacts that help organizations overcome the acceptance problems predicted by theory: "We argue that a combination of technology-based artifacts (e.g., system conceptualizations and representations, practices, technical capabilities, interfaces, etc.), organization based artifacts (e.g., structures, compensation, reporting relationships, social systems, etc.), and people-based artifacts (e.g., training, consensus building, etc.) are [sic] necessary to address such issues." (p. 84).

The term 'artifact' is being made to do some heavy lifting indeed, ranging from tangible bits of technology, such as software artifacts, through to intensely social artifacts, such as "consensus building". For any given design research project, the artifacts to be built need to be identified and boundaries drawn. If the boundaries are drawn in an inappropriate manner, for example productivity measures (a technologybased artifact) are introduced but the artifacts related to training, organizational support, and consensus building are not addressed then the DS project will likely fail to be accepted. Is this failure attributable solely to the technology-based artifact? To the organization-based and people -based artifacts?

There is a strong sense that problems are pre-existing in the world and that the role of design science is to identify these problems and to then propose solutions. This seems like a reasonable approach for technology-based artifacts, for which a set of requirements can be specified and a solution designed. It is not so apparent that the problem solving approach can be taken once the context of application for the artifact is taken into account and organizational/people based artifacts are included in the mix.

Linstone [14] has highlighted some shortcomings of the traditional perspective grounded in science and engineering. In this traditional worldview problems are defined with the assumption that they can be solved; Linstone (ibid.) argues that solving a problem creates new problems - we shift problems rather than solve them. Linstone also argues against reductionism (a reliance on data and models as the only 
legitimate means of enquiry), the analyst (design scientist) as objective observer; individuals as types (but not as unique persons); and a linear, universal model of time.

Linstone labels the traditional perspective as the technical $(T)$ perspective. Mitroff and Linstone [15] augment the technical view with organizational and personal views of a problem situation. The organizational $(O)$ perspective is concerned with social entities, processes, justice and fairness, the problem of the moment, and reasonableness. The personal $(P)$ perspective is concerned with individuation, power and influence, values and morality, challenges, and a need for beliefs [15].

These different perspectives are concerned with how we consider a problem situation. Linstone [16] justifies the use of multiple perspectives firstly on the grounds that "each perspective yields insights not obtainable with the others", and secondly "the $O$ and $P$ perspectives are essential in bridging the gap between analysis and action" (p. 314). Linstone [16] argues that the T perspective focuses on analysis, but must be supported by $\mathrm{O}$ and $\mathrm{P}$ analyses when moving to implementation. DS is dominated by technology-based artifacts within a $\mathrm{T}$ perspective, while successful implementation and evaluation will require attention to be given to organizationbased artifacts (O perspective) and people-based artifacts ( $\mathrm{P}$ perspective). In situations where the role of technology-based artifact is downplayed and the organization/ people-based artifacts take greater prominence, then DSR becomes largely indistinguishable from action research. Peffers et al. [11] "[i]n DS research, design and the proof of its usefulness is the central component, whereas in action research, the focus of interest is the organizational context and the active search for problem solutions therein" (p. 72).

Peffers et al. [11] then say that the resolution of this point is outside the scope of their paper. We suggest that a study of information systems will always, by definition (and based on the assumption that we are not computer scientists), include some aspect of the organizational context. Hevner et al. [6] go further and claim that this context should include a consideration of profit. Thus, while DSR is concerned with providing solutions to organizations the $O$ and $P$ perspectives will always have relevance. Sometimes, this relevance will be slight and a focus on technology-based artifacts is appropriate and the $O$ and $P$ dimensions have only weak effects. At the other end of the spectrum the $O$ and $P$ perspectives will be paramount and such a design science project would indeed be indistinguishable from action research (Fig.2).

(a)

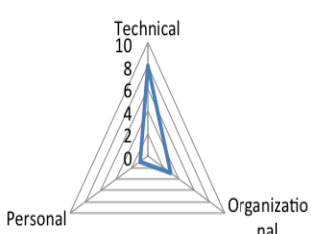

(b)

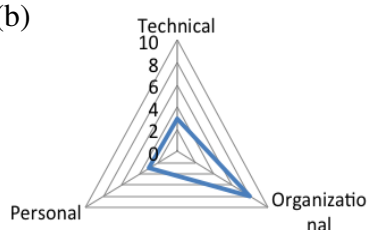

Fig. 2. Profiling design science and action research 
Our proposed DSR project has a substantial technology-based artifact content. In the first phase, we develop an agile measurement system based on lean principles. Evaluation of this artifact will involve agile team members and IS managers with an emphasis on technical rationality and the technology-based artifact rather than the $O$ and $P$ dimensions (Fig. 2a). A further evaluation will be needed to assess how well the agile measurement system works in an organizational context, at which time the technology-based artifact will need to be supplemented with organizational and people-based artifacts (Fig. 2b). The evaluation resembles an action research project.

\section{Conclusions and Future Research}

Despite the substantial amount of prior agile research, there is lack of hard evidence to support the effectiveness of agile methods $[2,17]$. To address this issue, the authors plan to identify and evaluate a set of measures for agile software development.

\section{References}

1. Schatz, B., Abdelshafi, I.: Primavera gets agile: a successful transition to agile development. IEEE Software 22, 36-42 (2005)

2. Conboy, K.: Agility from first principles: Reconstructing the concept of agility in information systems development. Information Systems Research 20, 329-354 (2009)

3. Vidgen, R., Wang, X.: Coevolving Systems and the Organization of Agile Software Development. Information Systems Research 20, 355-376 (2009)

4. Cross, N.: Engineering Design Methods: Strategies for Product Design. John Wiley \& Sons Ltd, Chichester (2008)

5. Iivari, J., Venable, J.R.: Action research and design science research-Seemingly similar but decisively dissimilar. In: European Conference on Information Systems, Verona, Italy (2009)

6. Hevner, A., March, S., Park, J.: Design Science in Information Systems Research. MIS Quarterly 28, 75-105 (2004)

7. Orlikowski, W.J., Iacono, C.S.: Research Commentary: Desperately Seeking the "IT" in IT Research. Information Systems Research 12, 121-134 (2001)

8. Benbasat, I., Zmud, R.: The Identity Crisis Within the IS Discipline: Defining and Communicating the Discipline's Core Properties. MIS Quarterly 27, 183-194 (2003)

9. Gregor, S., Hevner, A.R.: Introduction to the special issue on design science. Information Systems and e-Business Management 9, 1-9 (2011)

10. March, S.T., Smith, G.F.: Design and natural science research on information technology. Decision Support Systems 15, 251-266 (1995)

11. Peffers, K., Tuunanen, T., Rothenberger, M.A., Chatterjee, S.: A design science research methodology for information systems research. Journal of Management Information Systems 24, 45-77 (2007)

12. Schmidt, J., Lyle, D.: Lean Integration: An Integration Factory Approach to Business Agility. Addison-Wesley, Upper Saddle River (2010)

13. Ohno, T.: Toyota production system. Productivity, Portland (1988) 
14. Linstone, H.A.: Multiple perspectives: overcoming the weaknesses of MS/OR. Interfaces, 77-85 (1985)

15. Mitroff, I.I., Linstone, H.A.: The unbounded mind: Breaking the chains of traditional business thinking. Oxford University Press, USA (1995)

16. Linstone, H.A.: Multiple perspectives: concept, applications, and user guidelines. Systemic Practice and Action Research 2, 307-331 (1989)

17. Abrahamsson, P., Conboy, K., Wang, X.: 'Lots done, more to do': the current state of agile development research. European Journal of Information Systems 18, 281-284 (2009) 